\title{
Victoria Crowe: plant memory in a wider landscape
}

Plant Memory (2007) was an exciting Royal Scottish Academy exhibition of new works by the distinguished painter,Victoria Crowe. The works exhibited grew out of conversations Victoria and I had during the painting of my portrait as Master of St Catharine's College, Cambridge and subsequently during her tenure as a Visiting Scholar there. They included sensitive and exquisitely beautiful watercolours and oils, mixed media works and a limited edition of a remarkable handmade book, all inspired by pressed plants in the Herbaria of the University of Cambridge and the Royal Botanic Garden Edinburgh and by ancient herbals in botanical libraries in Scotland and Italy (Figure I). In parallel with Plant Memory, the Royal College of Physicians of Edinburgh held an exhibition of some of the rare and beautiful sixteenth century illustrated herbals from its own Library, for these had been amongst Crowe's most important sources of inspiration. I strongly urge you to visit (or revisit) the Exhibitions pages of the College website, http://www. rcpe.ac.uk/library/exhibitions/crowe/index.php where images from both exhibitions are still displayed.

Plant Memory has now been placed in the broader context of Crowe's complete output to date, in a monograph entitled Victoria Crowe, by the distinguished art historian and critic Duncan Macmillan (published in September 2012 by the Antique Collectors' Club, Woodbridge, Suffolk). I recommend it not only for its insightful and compellingly written text, in which Macmillan places Crowe's deeply thoughtful work in the wider historical context of European painting, but also for its lavish layout and large number of superbly reproduced images of Crowe's work. It is a veritable feast for both the mind and the eye.

Crowe's student years were spent at the Royal College of Art, followed by her move to Scotland and, amongst other new projects, the beginning of a series of sensitive paintings of Jenny, a shepherd who lived and worked at Kittleyknowe in the Borders, near the new home Crowe shared with her husband Mike Walton and their young family. These paintings were brought together for the first time in 2000, for the highly acclaimed exhibition A Shepherd's Life at the Scottish National Portrait Gallery. Set mainly in snowy landscapes or the cosy interior of Jenny's cottage, the paintings were a unique record of a courageous woman and her work, and a moving series of acutely observed portraits in a landscape, sometimes, as Macmillan says, 'portraits without a sitter'. It was through A Shepherd's Life that I first encountered Crowe's work and instantly decided that if I ever had to have my own portrait painted, Victoria Crowe would be my artist of choice.

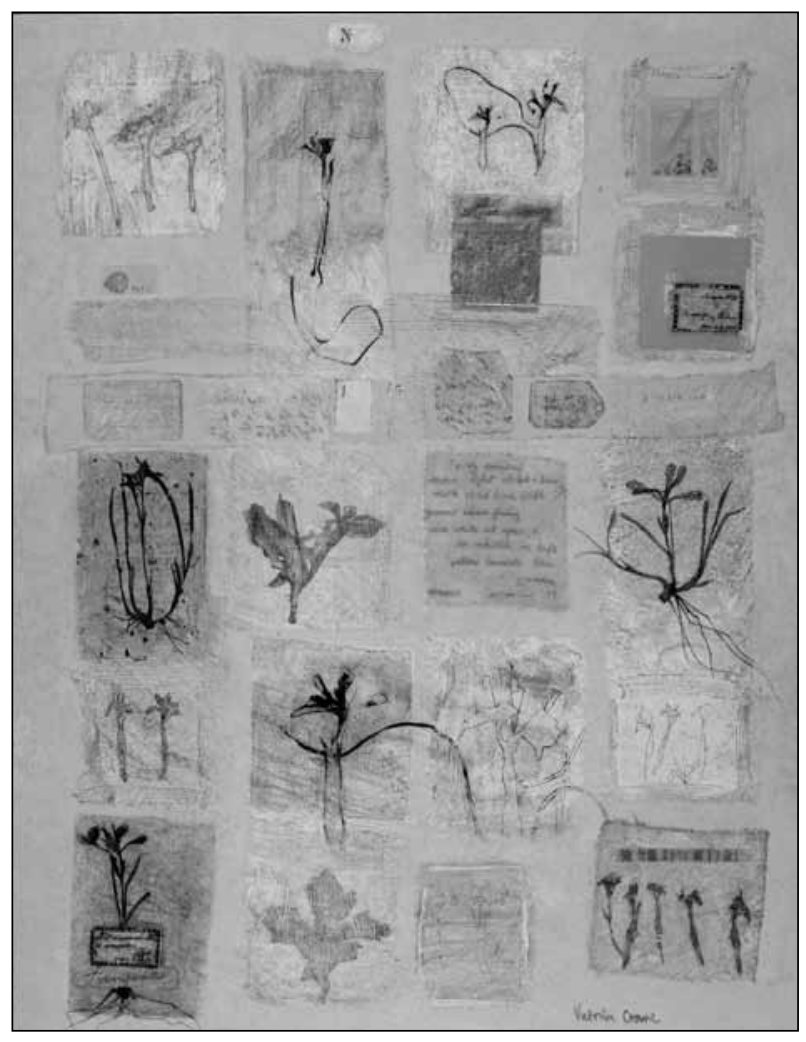

FIGURE I Victoria Crowe. Sign and symbol. Herbarium pages (2005). Oil and mixed media on linen.

Crowe's other portraits include, among many others, Kathleen Raine (for the National Portrait Gallery), whose poetry had been an important inspiration, the distinguished composer Thea Musgrave (for the Scottish National Portrait Gallery), Geoff Chisholm as President of the RCSEd and two recent Presidents of the RCPE. My own experience of being painted by Crowe is that she is able to enter the mind of the sitter in a unique way, revealing through her art intimate aspects of his or her personality that could never have been captured in a mere 'likeness'.

Crowe produced a series of paintings following her move to West Linton that are by turns enigmatic, deeply disturbing and visually stunning, many including, as part of the composition, a self portrait or an image of one of her children. This was a period of personal tragedy for Crowe, as well as being a time when the art and landscape of Italy, especially Venice, began to influence her work. Her palette became richer, with extensive use of Italian reds and a galaxy of colours derived from them. Moreover, as Macmillan puts it, she began to create in her paintings 'a pictorial space that is a metaphor for memory', many of them being collages of remembered 
fragments that seek to capture the passage of time, so apparent in the physical state of many paintings and buildings of the Italian Renaissance. Flowers and plants, often dramatic in form - such as orchids, proteas, trees and stately and deeply significant Madonna lilies - also began to recur with increasing frequency in Crowe's work at this time.

Appropriately, Plant Memory and other 'plant memories' followed. I have written elsewhere that in the herbarium specimens that form the basis for many of the works in this group, Crowe seems to me to have been inspired by the tension between timelessness and fragility that characterises not only herbarium specimens, but also many paintings, objects and cities in Italy, not least the city of Venice where she now spends a part of every year. Macmillan comments that in the exhibition

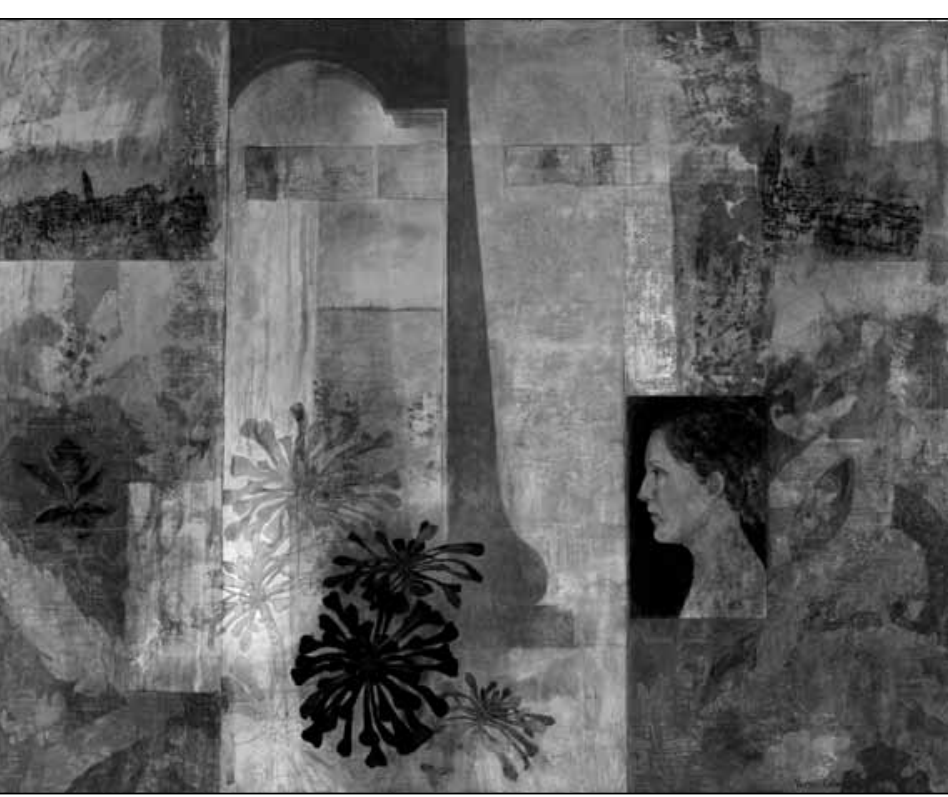

FIGURE 2 Victoria Crowe. Studio Venice, mirrored view (20II). Oil on linen.
Macmillan is careful to draw out Mike's indispensable role in Crowe's life, not only as husband and partner, but also as business manager, publicity agent, honest critic, editor and much, much more. The book ends with a kind of homecoming to the fragile, timeless beauty of the Venetian cityscape they both love, combined with countless other memories, in a series of gentle paintings of great subtlety and depth (Figure 2). 'the fragility and beauty of herbarium specimens .... is layered and combined with other things that extend [s] its relevance beyond botany to life itself and the role of memory in our understanding'.

Similarly, Crowe's subsequent dramatic paintings of trees, especially in winter, seem to capture the vital energy and movement of long-lived denizens of the landscape, in which the memories of countless generations are embodied, while at the same time harking back to her earlier paintings in the Shepherd's Life series. Rich blues become more apparent in Crowe's palette during this period and the silent, enfolding and forgiving beauty of snow occurs again and again. A recent project was the creation of a wonderful tapestry, based on a painting of Jenny from A Shepherd's Life and woven by the Dovecot Studios, in which the texture of the fabric and the soft colours of the yarns seem to imbue the image with a misty, diffuse character that is entirely new. Elsewhere, dogs scratch and sniff in Venetian calli and gentle greyhounds inhabit the landscape of Sienna and play elegant roles in a visually stunning series of paintings created especially for a house in the Scottish Borders. Mike Walton, Crowe's husband, played a leading creative role in the restoration and decoration of the principal rooms of this house, and it is most fitting that Duncan colours of her palette become deeper and richer as time goes by, so that her paintings appear to glow with an inner light.

\section{David Ingram,}

Honorary Professor, Edinburgh and Lancaster Universities; formerly Regius Keeper, the Royal Botanic Garden Edinburgh and then Master, St Catharine's College, Cambridge.

(email: d.ingram@lancaster.ac.uk) 